\title{
INTEGRAÇÃO DE PRÁTICAS CULTURAIS E REDUÇÃO DA DOSE DO BENTAZON NA CULTURA DA SOJA. I - EFEITOS SOBRE O CRESCIMENTO DA CULTURA ${ }^{1,2}$
}

\author{
FERNANDO T. DE CARVALHO ${ }^{3}$ e JÚLIO C. DURIGAN ${ }^{4}$
}

\section{RESUMO}

O trabalho foi desenvolvido no município de Jaboticabal, SP, no ano agrícola de 1990/91, onde testou-se a integração de práticas culturais e menor dose de herbicida aplicado em pósemergência na cultura da soja, cultivar Paraná. O delineamento experimental utilizado foi o de blocos ao acaso, com dezesseis tratamentos e quatro repetições, no esquema fatorial $4 \times 2 \times 2$, sendo quatro tipos de manejos de plantas daninhas: testemunha infestada, $50 \%$ da dose recomendada (360 g ia/ha) do herbicida bentazon, dose recomendada do herbicida bentazon $(720 \mathrm{~g} \mathrm{ia} / \mathrm{ha})$ e testemunha capinada; dois espaçamentos entre-linhas: $30 \mathrm{~cm}$ e $60 \mathrm{~cm}$; e duas densidades: normal e reduzida (média de 20 e 10 plantas por metro, respectivamente). Observou-se que a quantidade de matéria seca das plantas daninhas por época da colheita da soja, foi significativamente maior nos tratamentos com espaçamento maior e densidade reduzida. O arranjo proporcionado pela densidade normal (média de 20 plantas $/ \mathrm{m}$ ) e menor espaçamento (30 $\mathrm{cm})$ entre-linhas, proporcionou sombreamento mais precoce do solo e foi a melhor opção de controle cultural das plantas daninhas em todos os tratamentos testados. Não foi observado sintomas de intoxicação e nem efeitos negativos sobre a nodulação das plantas de soja, por parte do herbicida aplicado, em ambas as doses testadas.

Palavras chave: Planta daninha, controle cultural, herbicida, Glycine max.

\section{ABSTRACT \\ Integration of cultural practices and reduction of dose of bentazon on soybean crop I - Effects on the growth of crop}

This research was carried out during the growing season 1990/91, in Jaboticabal/SP. It tested the integration between crop practices and lower herbicide doses, sprayed in post-emergence for soybean crop, cultivar Parana. The experimental design was randomized blocks, with sixteen treatments and four replications, in four different weed management systems: infested control; controlled with $50 \%$ of the recommended $(0,751 \mathrm{pc} / \mathrm{ha})$ bentazon dose; controlled with the recommended bentazon dose (1,5 1 pc/ha) and a control kept clean; two spacings between rows:
$30 \mathrm{~cm}$ and $60 \mathrm{~cm}$; and two densities: normal and reduced (about 20 and 10 plants per meter, respectively). It was observed that the amount of dry matter of the weeds for time of the crop of the soy was significantly larger in the treatments with larger spacing and reduced density. The arrangement provided by the normal density (average of 20 plants $/ \mathrm{m}$ ) and smaller spacing $(30 \mathrm{~cm})$ among-lines provided more precocious shady of the soil and it was the best option of control of the weeds in all the tested treatments. It was not observed intoxication symptoms nor

\footnotetext{
${ }^{1}$ Recebido para publicação em 09/06/99 e na forma revisada em 15/12/98.

${ }^{2}$ Parte da dissertação do primeiro autor apresentada à FCAVJ para obtenção do título de Mestre em Produção Vegetal.

${ }^{3}$ Professor Mestre, FEIS/UNESP. Av. Brasil, 56, C.P. 31, Ilha Solteira/SP, CEP: 15385-000.

${ }^{4}$ Professor Livre Docente, FCAV/UNESP. Rod. Carlos Tonanni km 5, Jaboticabal/SP, CEP: 14870-000.
} 
negative effects on the nodulation of the soy plants, on the part of the applied herbicide, in both tested doses.
Key words: Weed, cultural control, herbicide, Glycine max..

\section{INTRODUÇÃO}

Existem diversos métodos para se controlar as plantas daninhas numa cultura, desde os mecânicos, os culturais e o controle químico. $\mathrm{Na}$ soja, devido à expansão de seu cultivo, o controle químico tem sido muito utilizado, em função do grande rendimento operacional, além de não apresentar problemas operacionais após as chuvas, situação que ocorre com os métodos mecânicos.

Atualmente, alguns trabalhos estão sendo feitos com o intuito de se diminuir as doses dos herbicidas, as quais normalmente são superestimadas, proporcionando períodos de controle maiores que os necessários (Durigan, 1983 e Rassini, 1988). Uma das formas utilizadas para se conseguir redução nas doses recomendadas dos herbicidas é a integração com certas práticas culturais.

Neste aspecto, têm-se destacado o estudo sobre a diminuição do espaçamento da cultura da soja, pois sabe-se que os 50 centímetros, usados convencionalmente, permitem grande penetração de luz entre as fileiras nos primeiros dois meses após a semeadura, o que favorece o crescimento das plantas daninhas justamente no "período crítico de prevenção da interferência (PCPI)" de tais plantas nesta cultura (Pitelli \& Durigan, 1984). Diversos pesquisadores tem demonstrado que, com a diminuição do espaçamento entrelinhas, ocorre um sombreamento mais precoce do solo, prejudicando o desenvolvimento das plantas daninhas e favorecendo a cultura na competição pelos fatores limitados do meio. Os trabalhos mais recentes, a respeito desse assunto, foram apresentados por Xavier \& Pinto (1988), Chemale et al. (1988), Rassini (1988), Légere \& Schreiber (1989), Shaw et al. (1991), Braz \& Durigan (1993a e 1993b) e Carvalho \& Durigan (1995).

Também são importantes os estudos de densidade, para que não se sobrecarregue a competição intra-específica, ao mesmo tempo não permitindo a ocorrência de espaços vazios pela falta de plantas, o que favoreceria $o$ desenvolvimento das infestantes em local que agrava a interferência entre ambas.

Os prejuízos da diminuição da densidade normal da soja, incrementando a interferência por parte das plantas daninhas e também desarranjando a cultura, foram observados por Marwat \& Nafziger (1990).

Portanto, a diminuição no espaçamento associada a uma adequada densidade de plantas na linha, é condição imprescindível para que a cultura, sombreando mais rapidamente, se beneficie na convivência com as plantas daninhas. A complementação do controle químico das plantas daninhas, proporcionada pelo sombreamento imposto pelas plantas cultivadas em função de tais modificações nas práticas culturais convencionais, é bastante desejável pois, além de manter ou até aumentar os níveis de produtividade, possibilita a redução dos custos de produção e do acúmulo de resíduos tóxicos no ambiente.

O objetivo do presente trabalho foi estudar os efeitos das alterações do arranjo cultural da cultura da soja, no crescimento lateral e vertical da cultura, e na ocorrência de plantas daninhas.

\section{MATERIAL E MÉTODOS}

O trabalho foi conduzido em área experimental da Faculdade de Ciências Agrárias e Veterinárias da Universidade Estadual Paulista/UNESP, Campus de Jaboticabal/SP, num Latossolo Vermelho Escuro distrófico, $A$ moderado, textura média.

O preparo do solo foi realizado de maneira convencional, ou seja, com uma aração e duas gradagens. A semeadura do experimento foi realizada no dia 28/11/1990. A emergência das 
plântulas da cultura ocorreu de quatro a seis dias após a semeadura. Os tratos culturais foram os normais exigidos pela cultura, no que diz respeito ao uso de inoculantes e controle de pragas. Não foram aplicados calcário e adubo, procurando-se, dessa maneira, não interferir no processo de competição intra e interespecífica das plantas cultivadas e daninhas. A colheita foi realizada em 31/03/91, retirando-se todas as plantas de soja da área útil $\left(4,8 \mathrm{~m}^{2}\right)$ de cada parcela, as quais foram levadas, aos feixes, para as avaliações em laboratório.

Cada parcela constou de seis linhas (para o espaçamento de $60 \mathrm{~cm}$ ) ou doze linhas (para o espaçamento de $30 \mathrm{~cm}$ ) com cinco metros de comprimento, totalizando-se $18 \mathrm{~m}^{2}$. O delineamento experimental adotado foi o de blocos ao acaso, com dezesseis tratamentos e quatro repetições, no esquema fatorial $4 \times 2 \times 2$. O cultivar de soja Paraná foi semeado em dois espaçamentos entre-linhas: $30 \mathrm{~cm}$ e $60 \mathrm{~cm}$; duas densidades: normal e reduzida (média de 20 e 10 plantas por metro, respectivamente); e com quatro tipos de manejo de plantas daninhas: testemunha infestada; $50 \%$ da dose recomendada $(0,75 \mathrm{l} / \mathrm{ha})$ do herbicida bentazon (Basagran - $480 \mathrm{~g} / \mathrm{l}$ ); dose recomendada do herbicida bentazon (1,5 l p.c./ha) e testemunha sempre capinada.

A aplicação do herbicida foi realizada com um pulverizador costal pressurizado $\left(\mathrm{CO}_{2}\right.$ a 40 psi), com volume de calda de 400 litros /ha. O herbicida foi aplicado em pós-emergência de ambos os tipos de plantas (cultivada e daninhas), no dia 13/12/90, ou seja, quatorze "dias após a semeadura" (DAS) da cultura. As plantas daninhas presentes na área estavam, em média, com dois a três pares de folhas.

Aos 30 DAA contou-se o número de plantas daninhas por $\mathrm{m}^{2}$ de cada parcela, utilizando-se de um retângulo metálico com $0,5 \mathrm{~m}$ de largura por 1,0 $\mathrm{m}$ de comprimento, perfazendo $0,5 \mathrm{~m}^{2}$ por amostra, que foi colocado em dois pontos de cada parcela, dentro da área útil. No tratamento em que a cultura permaneceu em convivência com a comunidade infestante durante todo o ciclo (Testemunha infestada), determinou- se também a porcentagem de infestação de cada espécie daninha.

Antes da colheita da cultura foram retiradas as plantas daninhas em $1,0 \mathrm{~m}^{2}$, dentro da área útil, para avaliação de sua matéria seca, após lavagem e secagem $\left(\mathrm{a} 60^{\circ} \mathrm{C}\right)$, até peso constante em estufa com circulação forçada de ar.

A avaliação do crescimento da cultura foi realizada medindo-se a distância entre os dosséis das fileiras vizinhas, em três pontos no centro da parcela, aos 40 DAS, e medindo-se a altura e o diâmetro do caule das plantas da cultura, no florescimento e na colheita, e a altura de inserção da primeira vagem e a contagem de nódulos na colheita.

\section{RESULTADOS E DISCUSSÃO}

As espécies daninhas que ocorreram no experimento estão apresentadas na Tabela 1. Podem ser consideradas como principais, com infestações superiores a $10 \%$, as seguintes dicotiledêneas: Sida rhombifolia L., Bidens pilosa L., Acanthospermum hispidum DC. e Alternanthera tenella Colla. Segundo Gelmini \& Diehl (1983) essas três espécies estão entre as principais dicotiledôneas que infestam a cultura da soja no Estado de São Paulo.

As variações do espaçamento e da densidade influíram no número de plantas daninhas nas respectivas parcelas. Na Tabela 1 estão apresentadas as quantidades de plantas daninhas que se desenvolveram nas testemunhas infestadas, o que possibilita a comparação dos efeitos das diferentes densidades e espaçamentos. Observa-se que o tratamento com menor densidade e maior espaçamento da cultura, possibilitou a emergência e desenvolvimento de maior número de plantas daninhas (815 indivíduos em $4 \mathrm{~m}^{2}$ ), sendo portanto, o menos efetivo como prática cultural de controle. Por outro lado, o tratamento com densidade normal e menor espaçamento foi o que apresentou o melhor controle cultural, tendo permitido o desenvolvimento de 318 plantas daninhas em $4 \mathrm{~m}^{2}$. Quando se combinou a densidade reduzida 
com $30 \mathrm{~cm}$ de espaçamento, foram contadas 536 plantas em $4 \mathrm{~m}^{2}$ e a densidade normal com $60 \mathrm{~cm}$ de espaçamento, 726 plantas daninhas em $4 \mathrm{~m}^{2}$.

Estes dados sugerem que a combinação da densidade e espaçamento podem proporcionar um arranjo cultural às plantas de soja que dificultam o crescimento das plantas daninhas. Estas observações, da influência do arranjo cultural sobre o controle das plantas daninhas, também foram mostradas por Maia et al. (1981).

TABELA 1. Porcentagem média de infestação das espécies daninhas nas testemunhas e suas respectivas quantidades de indivíduos na área útil, aos 50 DAS. Jaboticabal -SP, 1990/91.

\begin{tabular}{lcccc}
\hline & \multicolumn{4}{c}{$\begin{array}{c}\text { \% média de infestação das espécies } \\
\text { daninhas nas parcelas testemunhas }\end{array}$} \\
\cline { 2 - 5 } & $\mathrm{D}_{1} \mathrm{E}_{1}$ & $\mathrm{D}_{1} \mathrm{E}_{2}$ & $\mathrm{D}_{2} \mathrm{E}_{1}$ & $\mathrm{D}_{2} \mathrm{E}_{2}$ \\
\hline $\begin{array}{l}\text { Sida rhombifolia } \\
\text { (guanxuma) }\end{array}$ & 45,9 & 47,5 & 38,4 & 36,8 \\
$\begin{array}{l}\text { Bidens pilosa } \\
\text { (picão-preto) }\end{array}$ & 21,4 & 16,8 & 25,0 & 24,0 \\
$\begin{array}{l}\text { Acanthospermum hispidum } \\
\text { (carrapicho-de-carneiro) }\end{array}$ & 11,0 & 14,6 & 15,7 & 20,8 \\
$\begin{array}{l}\text { Alternanthera tenella } \\
\text { (apaga-fogo) }\end{array}$ & 8,8 & 6,5 & 8,8 & 8,1 \\
$\begin{array}{l}\text { Outras } \\
\text { Número total de plantas daninhas } \\
\text { em } 4 \text { m }\end{array}$ & 13,0 & 14,6 & 12,1 & 10,2 \\
\hline $\begin{array}{l}\mathrm{D}_{1}=\text { densidade normal } \\
\mathrm{D}_{2}=\text { densidade reduzida }\end{array}$ & 318 & 726 & 536 & 815 \\
$\mathrm{E}_{1}=30$ cm entre-linhas & & & & \\
$\mathrm{E}_{2}=60$ cm entre-linhas & & & & \\
\end{tabular}

Os diferentes tipos de manejo utilizados proporcionaram diferenças na rapidez de fechamento da cultura. Observa-se, pela Tabela 2, que os tratamentos mais eficientes no controle da comunidade infestante, proporcionaram $o$ fechamento mais rápido da cultura. Portanto a matointerferência afetou o crescimento total das plantas de soja, conforme observado também por Durigan (1983), Wyse et al. (1986) e Velini (1989).

Quanto às densidades testadas, observa-se que a reduzida condicionou maior crescimento lateral das plantas de soja, demonstrado pelas menores distâncias entre os dosséis, porém não indicando um sombreamento mais rápido do solo, pois as plantas de soja, nesta densidade, ficaram mais baixas (Tabela 3), o que favoreceu a penetração lateral da luz solar. Isto, associado ao fato que, nos tratamentos com densidade reduzida houve maior espaço livre para o crescimento das plantas daninhas, explicaria a menor infestação nos tratamentos com densidade normal.

O espaçamento foi a variável que proporcionou a diferença mais marcante no fechamento da cultura. Aos 40 DAS faltavam $4,75 \mathrm{~cm}$ para as plantas se tocarem nos tratamentos com $30 \mathrm{~cm}$ de espaçamento, enquanto que no espaçamento de $60 \mathrm{~cm}$ faltavam 13,53 cm. Estes resultados mostram ser o espaçamento, na cultura da soja, uma prática cultural bastante eficiente para a complementação do controle das plantas daninhas. Diversos pesquisadores já mostraram que, com a diminuição do espaçamento das entrelinhas, ocorre um sombreamento mais 
precoce e intenso do solo, prejudicando o favorecendo a cultura na competição pelos fatores desenvolvimento das plantas daninhas e limitados do meio.

TABELA 2. Médias dos dados de fechamento da cultura, e de matéria seca das plantas daninhas, em função dos manejos, densidades e espaçamentos estudados. Jaboticabal -SP, 1990/91.

\begin{tabular}{|c|c|c|}
\hline \multirow[b]{2}{*}{ Variáveis } & CULTURA & PLANTAS DANINHAS \\
\hline & $\begin{array}{c}\text { Distância entre dosséis } \\
\text { aos } 40 \text { DAS }(\mathrm{cm})\end{array}$ & Matéria seca na colheita $(\mathrm{g})$ \\
\hline \multicolumn{3}{|l|}{ MANEJO } \\
\hline Testem. Infestada & $10,0 \mathrm{a}$ & $645 \mathrm{a}$ \\
\hline Bentazon - $0,75 \mathrm{l} / \mathrm{ha}$ & $10,0 \mathrm{a}$ & $98 \mathrm{~b}$ \\
\hline Bentazon - 1,50 1/ha & $8,7 \mathrm{ab}$ & $56 \mathrm{~b}$ \\
\hline Test. Capinada & $7,9 \mathrm{~b}$ & $0 \mathrm{c}$ \\
\hline TESTE $\mathrm{F}$ & $7,10 * *$ & $522,78 * *$ \\
\hline \multicolumn{3}{|l|}{ DENSIDADE } \\
\hline 20 plantas /m (normal) & $10,6 \mathrm{a}$ & $174 \mathrm{~b}$ \\
\hline 10 plantas /m (reduz.) & $7,7 \mathrm{~b}$ & $225 \mathrm{a}$ \\
\hline TESTE $\mathrm{F}$ & $52,42 * *$ & $15,23 * *$ \\
\hline \multicolumn{3}{|l|}{ ESPAÇAMENTO } \\
\hline $30 \mathrm{~cm}$ & $4,75 \mathrm{~b}$ & $159 \mathrm{~b}$ \\
\hline $60 \mathrm{~cm}$ & $13,5 \mathrm{a}$ & $241 \mathrm{a}$ \\
\hline TESTE $\mathrm{F}$ & $499,82 * *$ & $38,97 * *$ \\
\hline $\mathrm{CV}(\%)$ & 17,2 & 4,1 \\
\hline
\end{tabular}

Obs.: Médias acompanhadas de letras iguais não diferem entre si a 5\% de probabilidade, pelo teste de Tukey.

Segundo Durigan (1983), o melhor controle das plantas daninhas proporciona a formação de maior e mais precoce área foliar da soja, com benefícios diretos na complementação do controle e consequentemente, na produtividade da cultura. Esta é a outra forma de se enfocar tal aspecto exposto anteriormente.

Os resultados da análise de variância e do teste de Tukey, para os dados relacionados à eficácia dos tratamentos no controle das plantas daninhas, estão apresentados na Tabela 2 . Observa-se que houve diferenças significativas na eficiência de controle das plantas daninhas, quando se alterou o tipo de manejo empregado, como era de se esperar. No entanto, constata-se também a influência de características estritamente relacionadas ao arranjo cultural, sobre a quantidade de matéria seca de plantas daninhas.
Observa-se que dentro do manejo, os tratamentos mais eficientes no controle das plantas daninhas, ou seja, que proporcionaram as menores quantidades de matéria seca acumulada pelas plantas daninhas por época da colheita, em ordem decrescente, foram os seguintes: testemunha capinada, dosagem normal do herbicida, 50\% da dosagem normal do herbicida e testemunha infestada. Da mesma maneira, os tratamentos com densidade normal e menores espaçamentos foram mais eficientes devido ao sombreamento mais precoce imposto por esses tratamentos, que auxiliou no controle das plantas daninhas, já que a maioria delas necessita de luz para germinar e se desenvolver. A quantidade de matéria seca de plantas daninhas na colheita foi estatisticamente igual entre os tratamentos com $50 \%$ e $100 \%$ da dose do herbicida. 
TABELA 3. Médias dos dados de crescimento da cultura, em função dos manejos, densidades e espaçamentos estudados. Jaboticabal -SP, 1990/91.

\begin{tabular}{|c|c|c|c|c|c|}
\hline \multirow[t]{2}{*}{ Variáveis } & \multicolumn{2}{|c|}{$\begin{array}{l}\text { Altura das plantas } \\
\qquad(\mathrm{cm})\end{array}$} & \multirow{2}{*}{$\begin{array}{l}\text { Diâmetro do } \\
\text { caule na } \\
\text { colheita } \\
(\mathrm{mm}) \\
\end{array}$} & \multirow{2}{*}{$\begin{array}{c}\text { Altura de } \\
\text { inserção da } \\
1^{\mathrm{a}} \text { vagem } \\
(\mathrm{cm}) \\
\end{array}$} & \multirow{2}{*}{$\begin{array}{c}\text { Peso matéria } \\
\text { seca de nódulo } \\
\text { no floresc. } \\
(\mathrm{g})\end{array}$} \\
\hline & Floresc. & Colheita & & & \\
\hline \multicolumn{6}{|l|}{ MANEJO } \\
\hline Testem. Infestada & $25,25 \mathrm{~b}$ & $4,22 \mathrm{~b}$ & $57,50 \mathrm{~b}$ & - & - \\
\hline Bentazon - 0,75 1/ha & $29,25 \mathrm{a}$ & $4,32 \mathrm{~b}$ & $58,38 \mathrm{ab}$ & - & - \\
\hline Bentazon - 1,50 1/ha & $28,56 \mathrm{a}$ & $4,58 \mathrm{a}$ & $59,50 \mathrm{ab}$ & - & - \\
\hline Test. Capinada & $29,31 \mathrm{a}$ & $4,78 \mathrm{a}$ & $62,19 \mathrm{a}$ & - & - \\
\hline TESTE $\mathrm{F}$ & $7,91 * *$ & $14,07 * *$ & $3,20 * *$ & $2,08^{\mathrm{NS}}$ & $0,04^{\mathrm{NS}}$ \\
\hline \multicolumn{6}{|l|}{ DENSIDADE } \\
\hline 20 plantas /m (normal) & $30,41 \mathrm{a}$ & $4,26 \mathrm{~b}$ & $60,78 \mathrm{a}$ & $11,53 \mathrm{a}$ & - \\
\hline 10 plantas /m (reduz.) & $25,78 \mathrm{~b}$ & $4,70 \mathrm{a}$ & $58,00 \mathrm{~b}$ & $10,83 \mathrm{~b}$ & - \\
\hline TESTE F & $45,6^{* *}$ & $42,69 * *$ & $5,97 * *$ & $13,71 * *$ & $2,65^{\mathrm{NS}}$ \\
\hline \multicolumn{6}{|l|}{ ESPAÇAMENTO } \\
\hline $30 \mathrm{~cm}$ & - & $3,80 \mathrm{~b}$ & $65,59 \mathrm{a}$ & $12,66 \mathrm{a}$ & - \\
\hline $60 \mathrm{~cm}$ & - & $5,16 \mathrm{a}$ & $53,19 \mathrm{~b}$ & $9,71 \mathrm{~b}$ & - \\
\hline TESTE $\mathrm{F}$ & $1,41^{\mathrm{NS}}$ & $406,31 * *$ & $118,9^{* * *}$ & $242,92 * *$ & $0,13^{\mathrm{NS}}$ \\
\hline $\mathrm{CV}(\%)$ & 9,8 & 6,0 & 7,7 & 6,8 & 34,6 \\
\hline
\end{tabular}

Obs.: Médias acompanhadas de letras iguais não diferem entre si a 5\% de probabilidade, pelo teste de Tukey.

Os resultados da análise de variância para os dados relacionados às características agronômicas da cultura, estão apresentados na Tabela 3. Observa-se que os diferentes tratamentos influenciaram significativamente nas características morfológicas relacionadas ao desenvolvimento das plantas.

A altura das plantas de soja foi influenciada pelas diferentes modalidades de manejo, densidades e espaçamentos. Vale ressaltar que a altura das plantas também auxilia no fechamento da cultura, dificultando a chegada de raios laterais de luz solar no solo. Desta forma, observando-se as diferenças nas médias de altura das plantas de soja, por época do florescimento, pode-se constatar que os tratamentos com herbicida, nas duas doses, proporcionaram plantas mais altas do que a testemunha infestada e estatisticamente iguais à testemunha capinada. Da mesma maneira, nos tratamentos com densidade normal e $30 \mathrm{~cm}$ de espaçamento, as plantas foram mais altas e auxiliaram no controle das plantas daninhas, concordando com trabalhos de Durigan (1983) e Wyse et al. (1986) que demonstraram que a matointerferência prejudica o crescimento vertical das plantas de soja.

Outras observações a respeito da altura de plantas, podem ser feitas para algumas interações que apresentaram efeitos significativos. Com densidade reduzida e $30 \mathrm{~cm}$ de espaçamento, os diferentes manejos não influenciaram na altura das plantas. Com densidade normal e $60 \mathrm{~cm}$ de espaçamento, apenas a testemunha infestada, dentro do manejo, apresentou-se com plantas mais baixas. Onde o efeito da interferência das plantas daninhas foi menor (tratamentos com 100\% da dosagem do herbicida e testemunhas capinadas) houve maior crescimento das plantas de soja na densidade normal do que na reduzida. Este efeito não foi observado nos tratamentos com $50 \%$ da 
dosagem do herbicida e testemunha infestada porque as plantas daninhas que surgiram, prejudicaram o crescimento das plantas de soja como discutido anteriormente. Por outro lado, observou-se que em quaisquer dos manejos, a altura foi sempre maior quando o espaçamento foi menor (Tabela 4).

TABELA 4. Médias dos dados relacionados às características agronômicas da cultura, cujas interações entre os tratamentos foram significativas. Jaboticabal -SP, 1990/91.

\begin{tabular}{|c|c|c|c|c|c|c|c|c|}
\hline \multirow[t]{2}{*}{ Variáveis } & \multicolumn{8}{|c|}{ Distância lateral entre dosséis aos 40 DAS (cm) } \\
\hline & \multicolumn{4}{|c|}{ Densidade normal } & \multicolumn{4}{|c|}{ Densidade reduzida } \\
\hline Espaç. $30 \mathrm{~cm}$ & \multicolumn{4}{|c|}{ A $5,5 \mathrm{~b}$} & \multicolumn{4}{|c|}{ B $4,0 \mathrm{~b}$} \\
\hline Espaç. $60 \mathrm{~cm}$ & \multicolumn{4}{|c|}{ A 15,6 a } & \multicolumn{4}{|c|}{ B $11,4 \mathrm{a}$} \\
\hline \multirow[t]{2}{*}{ Variáveis } & \multicolumn{8}{|c|}{ Matéria seca de plantas daninhas na colheita $\left(\mathrm{g} / \mathrm{m}^{2}\right)$} \\
\hline & \multicolumn{2}{|c|}{ M1 } & \multicolumn{2}{|c|}{ M2 } & \multicolumn{2}{|c|}{ M3 } & \multicolumn{2}{|c|}{ M4 } \\
\hline Espaç. $30 \mathrm{~cm}$ & \multicolumn{2}{|c|}{ A $521,9 \mathrm{~b}$} & \multicolumn{2}{|c|}{ B 72,7 a } & \multicolumn{2}{|c|}{ BC $40,4 \mathrm{a}$} & \multicolumn{2}{|c|}{$\mathrm{C} 0,0 \mathrm{a}$} \\
\hline Espaç. $60 \mathrm{~cm}$ & \multicolumn{2}{|c|}{ A $768,6 \mathrm{a}$} & \multicolumn{2}{|c|}{ B $122,9 \mathrm{a}$} & \multicolumn{2}{|c|}{ B $70,9 \mathrm{a}$} & \multicolumn{2}{|c|}{$\mathrm{C} 0,0 \mathrm{a}$} \\
\hline \multirow[t]{2}{*}{ Variáveis } & \multicolumn{4}{|c|}{ Altura no florescimento $(\mathrm{cm})$} & \multicolumn{4}{|c|}{ Altura na colheita $(\mathrm{cm})$} \\
\hline & M1 & M2 & M3 & M4 & M1 & M2 & M3 & M4 \\
\hline Densid. normal & $\mathrm{B} 25,2 \mathrm{a}$ & A30,4 a & A32,1 a & A33,9 a & A67,8 a & A62,6 a & $\mathrm{A} 65,0 \mathrm{a}$ & $\mathrm{A} 67,0 \mathrm{a}$ \\
\hline Densid. reduz. & $\mathrm{A} 25,2 \mathrm{a}$ & $\mathrm{A} 28,1 \mathrm{a}$ & $\mathrm{A} 25,0 \mathrm{~b}$ & $\mathrm{~A} 24,8 \mathrm{~b}$ & $\mathrm{~B} 47,2 \mathrm{~b}$ & $\mathrm{~A} 54,1 \mathrm{~b}$ & $\mathrm{~A} 54,0 \mathrm{~b}$ & $\mathrm{~A} 57,4 \mathrm{~b}$ \\
\hline \multirow[t]{2}{*}{ Variáveis } & \multicolumn{4}{|c|}{ Altura no florescimento $(\mathrm{cm})$} & \multicolumn{4}{|c|}{ Altura na colheita $(\mathrm{cm})$} \\
\hline & \multicolumn{2}{|c|}{ Densid. normal } & \multicolumn{2}{|c|}{ Densid. reduz. } & Densid & normal & Densid. & Reduz. \\
\hline Espaç. $30 \mathrm{~cm}$ & A 31 & $75 \mathrm{a}$ & B 25 & $25 \mathrm{a}$ & A 68 & $75 \mathrm{a}$ & B 62 & $44 \mathrm{a}$ \\
\hline Espaç. $60 \mathrm{~cm}$ & A 29 & $6 \mathrm{~b}$ & B 26 & $31 \mathrm{a}$ & A 52 & $81 \mathrm{~b}$ & A 53 &, $56 \mathrm{~b}$ \\
\hline Variáveis & & & Altu & a inserção & $\underline{a}$ vagem & & & \\
\hline & $\mathrm{N}$ & & $\mathrm{M}$ & & & & $\mathrm{N}$ & 14 \\
\hline Densid. normal & $\mathrm{A} 1$ & & A11 & & $\bar{A} 1$ & & $\bar{A} 11$ &, $5 \mathrm{a}$ \\
\hline Densid. reduz. & B9. & & $\mathrm{AB} 1$ &, $9 \mathrm{a}$ & A1 & & A11 &, $4 \mathrm{a}$ \\
\hline Variáveis & & âmetro do & aule $(\mathrm{mm}$ & & Altu & a inserção & ${ }^{\mathrm{a}}$ vagem $(\mathrm{c}$ & \\
\hline & M1 & M2 & M3 & M4 & M1 & M2 & M3 & M4 \\
\hline Espaç. $30 \mathrm{~cm}$ & $\mathrm{~B} 3,5 \mathrm{~b}$ & $\mathrm{~B} 3,6 \mathrm{~b}$ & $\mathrm{~A} 4,0 \mathrm{~b}$ & $\mathrm{~A} 4,1 \mathrm{~b}$ & A12,9 a & $\mathrm{A} 12,5 \mathrm{a}$ & $\mathrm{A} 12,7 \mathrm{a}$ & A12,5 a \\
\hline Espaç. $60 \mathrm{~cm}$ & $\mathrm{~B} 5,0 \mathrm{a}$ & $\mathrm{B} 5,0 \mathrm{a}$ & $\mathrm{AB} 5,2 \mathrm{a}$ & $\mathrm{A} 5,5 \mathrm{a}$ & $\mathrm{B} 8,8 \mathrm{~b}$ & $\mathrm{AB} 9,6 \mathrm{~b}$ & $\mathrm{~A} 10,0 \mathrm{~b}$ & $\mathrm{~A} 10,4 \mathrm{~b}$ \\
\hline Variáveis & & âmetro do & aule $(\mathrm{mm}$ & & Altu & a inserção & ${ }^{\mathrm{a}}$ vagem $(\mathrm{c}$ & \\
\hline & Densid. & normal & Densid. & eduzida & Densid & normal & Densid & reduz. \\
\hline Espaç. $30 \mathrm{~cm}$ & B 3 & & A 4 & & A 1 & $3 \mathrm{a}$ & A 1 & $2,0 \mathrm{a}$ \\
\hline Espaç. $60 \mathrm{~cm}$ & B 5 & & A 5 & & & & A 9 & $6 \mathrm{~b}$ \\
\hline M1 = testemunha inf & da $\quad M$ & $50 \%$ da do & normal c & herbicide & & & & \\
\hline M3 = dosagem norm & lo herbicid & bentazon & M4 = & testemunha & pinada & & & \\
\hline
\end{tabular}

Observou-se também que tanto nos espaçamentos de $30 \mathrm{~cm}$ como nos de $60 \mathrm{~cm}$, as plantas cresceram significativamente mais com a densidade normal do que com a densidade reduzida, exceto para $60 \mathrm{~cm}$ na avaliação da colheita, que não apresentou diferenças na altura das plantas entre as duas densidades. Por outro lado, tanto na densidade normal como na reduzida, 
o espaçamento de $30 \mathrm{~cm}$ apresentou plantas significativamente maiores do que no de $60 \mathrm{~cm}$, exceto para densidade reduzida, na avaliação feita no florescimento, que não apresentou tais diferenças na altura das plantas entre os dois espaçamentos.

O diâmetro do caule, foi significativamente maior nos tratamentos com $100 \%$ da dose do herbicida e testemunha capinada do que nos tratamentos com 50\% da dosagem do herbicida e testemunha infestada. A maior infestação das plantas daninhas deixaram as plantas de soja mais finas, além de menores.

Os tipos de manejo não provocaram diferenças na altura de inserção da $1^{\mathrm{a}}$ vagem nos tratamentos. Nos tratamentos com $60 \mathrm{~cm}$ de espaçamento e densidade reduzida, a cultura apresentou altura de inserção da $1^{\underline{a}}$ vagem, significativamente, mais baixa.

Dentro das diferentes densidades e espaçamentos, observa-se uma relação inversa entre altura e diâmetro do caule, e direta entre altura das plantas e altura de inserção da $1^{\mathrm{a}}$ vagem.

Nos tratamentos com maiores quantidades de plantas de soja por área (densidade normal e espaçamento de $30 \mathrm{~cm}$ ) a cultura ficou com plantas maiores e mais finas, caracterizando-se um leve estiolamento devido ao aumento da competição intraespecífica, sem contudo, provocar acamamento. Essa informação também foi relatada por Rassini (1988) e Weber et al. (1966) que citaram que altas populações de soja produzem plantas mais altas, mais acamadas e com poucas vagens e sementes, quando comparadas às plantas mantidas em densidades menores.

Nos tratamentos com densidade normal e $30 \mathrm{~cm}$ de espaçamento, observou-se maiores alturas de inserção da primeira vagem, o que é uma característica interessante pois acarreta em menores perdas de grãos por ocasião da colheita mecanizada.

O diâmetro do caule, tanto no espaçamento de $30 \mathrm{~cm}$ como no de $60 \mathrm{~cm}$, foi significativamente maior nos tratamentos com $100 \%$ da dosagem do herbicida e testemunha capinada do que nos tratamentos com $50 \%$ da dosagem do herbicida e testemunha infestada. A maior infestação das plantas daninhas deixaram as plantas de soja mais finas, além de não terem ficado mais altas. $\mathrm{O}$ diâmetro do caule foi maior quando a densidade foi reduzida, independentemente do espaçamento. Também sempre foi maior quando se aumentou o espaçamento, independentemente da densidade utilizada (Tabela 4).

Os tipos de manejo não provocaram diferenças na altura de inserção da $1^{\underline{a}}$ vagem nos tratamentos com $30 \mathrm{~cm}$ de espaçamento e densidade normal. Nos tratamentos com $60 \mathrm{~cm}$ de espaçamento e densidade reduzida, apenas a testemunha infestada apresentou altura de inserção da $1^{\mathrm{a}}$ vagem, mais baixa, significativamente, em relação aos demais tratamentos.

Nos diferentes manejos, a altura de inserção da $1^{\text {a }}$ vagem foi sempre maior nos tratamentos com densidade normal e espaçamento de $30 \mathrm{~cm}$, do que nos tratamentos com densidade reduzida e $60 \mathrm{~cm}$ de espaçamento, confirmando os dados discutidos anteriormente sobre a relação direta entre a altura de plantas e altura de inserção da $1^{\mathrm{a}}$ vagem.

A altura de inserção da $1^{\mathrm{a}}$ vagem foi maior na densidade normal do que na densidade reduzida dentro do espaçamento de $30 \mathrm{~cm}$ e semelhante dentro do espaçamento de $60 \mathrm{~cm}$. Também foi maior no espaçamento de $30 \mathrm{~cm}$ do que no de 60 $\mathrm{cm}$ tanto na densidade normal como na reduzida.

Em todos os tratamentos, as plantas produziram nódulos estatisticamente iguais, sugerindo que a aplicação do herbicida não influenciou na quantidade de nódulos produzidos, concordando com Rassini (1988) que também não encontrou diferenças na nodulação de plantas de soja em função do uso de herbicidas.

Nas condições na qual o experimento foi conduzido, pode-se concluir que a quantidade de matéria seca das plantas daninhas por época da colheita da soja, foi significativamente maior nos tratamentos com espaçamento maior e densidade reduzida. $\mathrm{O}$ arranjo proporcionado pela densidade normal (média de 20 plantas $/ \mathrm{m}$ ) e o menor espaçamento $(30 \mathrm{~cm})$ entre-linhas, permitiu 
melhor controle cultural da comunidade infestante. Não foi observado sintomas de intoxicação e nem efeitos negativos sobre a nodulação das plantas de soja, por parte do herbicida aplicado, em ambas as doses testadas.

\section{LITERATURA CITADA}

BRAZ, B.A., DURIGAN, J.C. Efeitos da redução do espaçamento e dosagens de herbicidas no controle de plantas daninhas, em duas épocas de semeadura da soja (Glycine max). In: CONGRESSO BRASILEIRO DE HERBICIDAS E PLANTAS DANINHAS, 19, 1993, Londrina. Resumos... Londrina: SBHED, 1993. p.97-99.

BRAZ, B.A., DURIGAN, J.C. Redução de espaçamento e sub-dosagens de herbicidas aplicados em pós-emergência, para o controle de plantas daninhas, em soja (Glycine max). In: CONGRESSO BRASILEIRO DE HERBICIDAS E PLANTAS DANINHAS, 19, 1993, Londrina. Resumos... Londrina: SBHED, 1993. p.96-97.

CARVALHO, F.T., DURIGAN, J.C. Integração de práticas culturais e redução da dose do bentazon na cultura da soja. Planta Daninha, v.13, n.1, p.46-49, 1995.

CHEMALE, V.M., VARGAS, J.R.N., SCHMIDT, M.M. Efeito de três espaçamentos e duas épocas de capina, no controle de plantas daninhas, em três cultivares de soja. In: CONGRESSO BRASILEIRO DE HERBICIDAS E PLANTAS DANINHAS, 17, 1988, Piracicaba. Resumos... Piracicaba: SBHED, 1988. p. 172.

DURIGAN, J.C. Matocompetição e comportamento de baixas doses de herbicidas, na cultura da soja [Glycine $\max ($ L.) Merrill]. Piracicaba: USP-ESALQ, 1983. 163 p. Tese Doutorado.

GELMINI, G.A., DIEHL, S.R.L. Controle de plantas daninhas na cultura da soja. Campinas: CATI, 1983. 23 p. (CATI. Boletim Técnico, 170).

LÉGERE, A., SCHREIBER, M.M. Competition and canopy architecture as affected by soybean (Glycine max) row width and density of redroot pigweed (Amaranthus retroflexus). Weed Sci., v.37, n.1, p. 84-92. 1989.

MAIA, A.C., REZENDE, A.M., LACABUENDIA, J.P. Efeito do espaçamento e população de plantas no controle de plantas daninhas na cultura da soja [Glycine $\max (\mathrm{L}$. Merrill] em solo de cerrado. In: SEMINÁRIO NACIONAL DE PESQUISA DE SOJA, 2, 1981, Brasília. Anais... Londrina: EMBRAPA - CNPSO, 1981. p.331-338.

MARWAT, K.B., NAFZIGER, E.D. Cocklebur and velvetleaf interference with soybean grown at different densities and planting patterns. Agron. J., v.82, n.3, p.531-534, 1990.

PITELLI, R.A., DURIGAN, J.C. Terminologia para períodos de controle e de convivência das plantas daninhas em culturas anuais e bianuais. In: CONGRESSO BRASILEIRO DE HERBICIDAS E PLANTAS DANINHAS, 15, 1984, Belo Horizonte. Resumos... Piracicaba: SBHED, 1984. p.37.

RASSINI, J.B. Integração de práticas culturais e baixas dosagens de herbicidas em pósemergência, para o controle de plantas daninhas na cultura da soja [Glycine max (L.) Merrill]. Jaboticabal: UNESP-FCAV, 1988. 115 p. Tese Doutorado. 
SHAW, D.R., BRUFF, S.A., SMITH, C.A. Effect of soybean (Glycine max) row spacing on chemical control of sicklepod (Cassia obtusifolia). Weed Technol., v. 5, n.2, p. 286- 290, 1991.

VELINI, E.D. Avaliação dos efeitos de comunidades infestantes naturais, controladas por diferentes períodos, sobre o crescimento e produtividade da cultura da soja [Glycine max (L.) Merrill]. Jaboticabal: UNESP-FCAV, 1989. 153 p. Dissertação (Mestrado em Agronomia) Faculdade de Ciências Agrárias e Veterinárias, Universidade Estadual Paulista, 1989.

WEBER, C.R., SHIBLES, R.M., BYTH, D.E. Effect of plant population and row spacing on soybean development and production. Agron. J., v.58, p.99-102, 1966.

XAVIER, F.E., PINTO, J.J.O. Redução da dosagem de herbicida, em pós-emergência, em função da utilização de menores espaçamentos de semeadura da soja. In: CONGRESSO BRASILEIRO DE HERBICIDAS E PLANTAS DANINHAS, 17, 1988, Piracicaba. Resumos... Piracicaba: SBHED, 1988. p.146-147.

WYSE, D.L., YOUNG, F.L., JONES, R.J. Influence of Jerusalen artichoke (Helianthus tuberosos) density and duration of interference on soybean (Glycine max) growth and yield. Weed Sci., v. 2, n. 34, p. 243 - 247, 1986. 